\title{
Social Behaviors in Nuclear and Extended families Children Age 6 to 11 - A Longitudinal Study with Turkish Sample
}

\author{
Serdal Seven and Mehmet Akif İnci
}

\begin{abstract}
The main aim of this study is to identify whether or not the social behaviors such Prosociality, Shyness and Aggression of children, living in a stable life period families, are stable from age 6 to age 11 in a sample of Turkish children. In total, 47 children participated in the study, of whom 24 male and 23 female lived in families in Muş Province, Turkey. Teacher Assessment of Social Behaviors Scale were applied to the same group four times (at ages $6,7,9,11$ ) in five years. The children in this sample were assessed initially at the end of their final preschool year (age 6) and were reassessed at the end of the first (age 7), third (age 9) and fifth grade (age 11) of elementary school. All assessments were conducted in May. In conclusion, social behavior was found to be stable for $55 \%$ prosocial behaviors, $31 \%$ Shynese behavior and $79 \%$ for aggressive behavior as results of regression analysis. These findings support the argument that aggression and prosocial behaviors follows a stable course from age 6-11 age onwards. Repeated measures ANOVA with a Greenhouse-Geisser correction determined that mean not differed statistically significantly between aggression's $(F(2.19,98.56)=.235, P>$ $0.05)$, shyness' $(F(2.92,131.58)=.982, P>0.05)$ and prosocial behaviours' $(F(2.63,118.67)=.383, P>0.05)$ time points and family types.
\end{abstract}

Index Terms-Aggression, shyness, prosocial behaviors, middle childhood, nuclear family, extended family.

\section{INTRODUCTION}

During the past 20 years suggests that children who do not have a basic level of social competence by the age of 6 may have trouble with relationships when they are adults. Thus, all children should have enough positive social behaviours [1]. The term "social competence" covers a broader domain than does the term "social behaviors". Social behaviors' characters are the strong aspect for observing social competence. Aggression, prosocial behavior and shyness are determinative social behaviors.

Aggression has been defined [2] as 'a category of behaviour that causes or threatens physical harm to others'. 'Aggression' as generally used is encompasses a variety of behaviours, including physical fighting, bullying, verbal aggression, robbery, homicide, and rape. Any behaviour aimed to harm someone or something, even if the source aimed at is not directly harmed, is considered to be aggression. Aggressive behaviour is a special form of anti-social behaviour [3]. Even though aggression is not a

Manuscript received August 19, 2014; revised October 20, 2014.

The authors are with the Muş Alparslan University, Güzeltepe Kampüsü, Güzeltepe 49100 Muş, Turkey (e-mail: s.seven@alparslan.edu.tr, mehmetakifinci@gmail.com). new concept, it has become an issue discussed more frequently in recent years. The increasing rate of aggression displayed by children has caused an increase in the number of studies carried out to assess aggression.

Although historically shyness has been a difficult term to define, recent efforts have sought to clarify the term for its inclusion in research. Shyness can be conceptualized as a feature of the larger category of social withdrawal, which encompasses many forms of behavioural solitude [4]. Shy children are often described as hesitant to participate in social interactions [5] and although research has suggested that they want to play with other children, social fear and anxiety prevent them from doing so [6].

Shyness has been found to be moderately consistent in early childhood [7]. Shyness has been relevant to problems with peers and with adjustment problems such as internalizing [8], [9], it is vital to identify variables that contribute to its development. Children are subjected to a great variety of environmental influences as they age, such as parenting behavior, the relationship between brothers and peers at day care, and these experiences could have implications for the development of shyness.

Humans are different from other species in terms of features such as the level of assistance, collaboration, and abnegation [10]. Prosocial behavior, that is, behavior intended to help others [11], is known as the fundamental component of human relationships [12]. Prosocial children get on with other children and have better relationships than children who have lower in prosocial behavior [13].

Besides wide parenting styles, parents ensure a socialization system for their children, and parent's prosocial behaviors have been proved to relate to children's behaviors. For instance, mothers of 6- to 11-year-olds claimed that they felt peaceful about using a reward system for developing children's prosocial behavior [14]. For these children, rewards damaged subsequent prosocial behavior [14]. On the contrary, there is proof that doing household works made children to concern for others [15].

According to the number of household members, families are generally classified as nuclear, extended, or fragmented [16]. In the assessment of family types in Turkey, classification is generally made according to the number of household members, following from recent social, cultural, and sociological changes and the process of modernization. In Turkey, as in many societies, modernization is the most important factor that has altered the family structure. As a result of modernization, which has gained pace since the 19th century, the family structure has changed and the number of 
nuclear families has increased and become more widespread compared to the number of extended families [17], [18]. Significant social developments in Turkey in recent years, such as migration from rural areas to urban areas and the inclusion of women in business as a result of an increase in their education level, have led to changes in the family structure. Although the nuclear family structure is gradually becoming more widespread, especially in big cities, extended families are commonly found in small cities and villages. Relationships have a definite form in nuclear families with an only child. These are child-mother, mother-father, child-father, and mother-father-child forms. When it comes to extended families, in which members such as grandmothers, grandfathers, aunts, and uncles exist, relationships become more complicated. In extended families, more than one generation can live together in the same house. On the contrary, a fragmented family is defined as a family type in which either the mother or the father or both is absent from the house because to reasons such as death, divorce, or separation [19], [20], [16], [21], [22]. In this study, nuclear and extended family types are discussed. Nuclear families consist of the mother, the father, and their children. Extended families include the mother, the father, and children as well as close relatives such as grandfathers, grandmothers, or aunts.

The question regarding the stability of aggression, shyness and prosocial behaviors in childhood seems not to be whether these social behaviors is stable or not stable. Regardless whether social behaviors are examined in short-term or long-term studies [23], [24]. Here are some longitudinal studies' results about aggression, prosocial behavior and shyness: Asendorpf [25], Degnan et al. [26], Prior et al. [27] and Roberts and del Vecchio [28] reported low stability of shyness before middle childhood. In conterast for shyness, Adams, Bukowski \& Bagwell [23], Loeber [29], Loeber \& Hay [7] and Olweus [30] found high stability about aggression. Similarly Knafo \& Plomin, [31] found middle level stability for prosocial behaviors.

Finally, there are limited long-term longitudinal studies about social behaviors for 6-11 years old children. In this respect, this study has attempted to answer the following questions:

1) Do aggression scores at age 6 significantly predict aggression scores at age 11 ?

2) Do shyness scores at age 6 significantly predict shyness scores at age 11 ?

3) Do prosiocial behavior scores at age 6 significantly predict prosocial behaviors scores at age 11 ?

4) Do mean of aggression's, shyness and prosocial behaviours differed or not statistically significantly between time points and family types

\section{METHOD}

A longitudinal method was used in this study.

\section{A. Participants}

The participants were 47 preschoolers (23 girls and 24 boys) with normal development from six preschools in the region of Muş Province, Turkey. The children in this sample were assessed initially at the end of their final preschool year (age 6) and were reassessed at the end of the first, third and fifth grade of elementary school (age 7, 9, 11). The children were located at 12 different schools after the school transition (preschool to elementary). All of the children lived with both parents. The socio-economic levels of the families were based on their level of income. Families with a monthly income of $\$ 500$ or less were included in the lower socio-economic level; families with an income between $\$ 500-1500$ were included in the middle socio-economic level; and those with an income of more than $\$ 1500$ were included in the higher socio-economic level.

\section{1) Demographic data about the nuclear families}

Of the nuclear families, $12.5 \%(n=3)$ were at the lower socioeconomic level, $70.8 \% \quad(n=17)$ were at the middle socioeconomic level, and $16,6 \%(n=4)$ were at the higher socioeconomic level. With regard to the education level of the mothers in the nuclear families, $16.6(n=4)$ of the mothers were illiterate, $50 \%(n=12)$ were primary school graduates, $20.8(n=5)$ were high school graduates, and 12,5\% $(n=3)$ were university graduates. With regard to the fathers in the nuclear families: 4,2\% $(n=1)$ were illiterate, 20,8\% $(n=5)$ were primary school graduates, $33.2 \%(n=8)$ were high school graduates, and $41,6 \% \quad(n=10)$ were university graduates. All of the children in the group had at least one sibling. Four of the children $(16.6 \%)$ had one sibling, whereas 20 children $(83.3 \%)$ had two siblings.

\section{2) Demographic data about the extended families}

Of the extended families, $34.8 \%(n=8)$ were at the lower socioeconomic level, $56.5 \% \quad(n=13)$ were at the middle socioeconomic level, and $8.7 \%(n=2)$ were at the higher socioeconomic level. With regard to the education level of the mothers in the extended families, $34.8 \%(n=8)$ of the mothers were illiterate, $52.2 \%(n=12)$ were primary school graduates, and $13 \%(n=3)$ were high school graduates. With regard to the fathers in the nuclear families, $17.4 \% \quad(n=4)$ were illiterate, $30.45 \%(n=7)$ were primary school graduates, $39.15 \%(n=9)$ were high school graduates, and $13 \%(n=3)$ were university graduates. All of the children in the group had at least two siblings. Thirteen of the children (56.5\%) had two siblings, and 10 children (44.5\%) had three siblings. Moreover, these families included at least two other adults, such as grandmothers, grandfathers, uncles, or aunts, in addition to the mother, the father, and their children. During the period of the study, there were no significant changes in the demographic statuses of the children participating in the study.

\section{B. Measure}

Teacher Assessment of Social Behavior (TASB): Children's social behavior in the peer group was assessed with the TASB. Teachers were asked to rate children on four behavioral dimensions: prosocial, aggressive, shy/withdrawn, and disruptive. Each dimension was assessed using three items, for a total of 12 items. The scale ranged from a 1 (very uncharacteristic) to a 5 (very characteristic). Cronbach's alpha coefficient was from .88 to .91 for eachdimension. The TASB was adapted to Turkish by Seven [32]. All items 
loaded on three dimensions (prosocial, shy/withdrawn, and aggressive/disruptive), with loadings ranging from .63 to .89 . Cronbach's alpha coefficient ranged from .74 to .94 for these dimensions.

\section{Procedure}

In 2006, a letter explaining our study was sent to the families of 110 children of 6 years of age who had attended six preschools. In the letter, they were asked whether or not they wanted their children to participate in our study. They were requested to fill in the information form and to send it back to us if they gave their consent for their child's participation. Seventy-two families gave their consent for their children's participation in our study. Five years later, the families of 21 of the children had moved to another city. One of the children had lost his mother. Therefore, information was gathered from 47 children, 23 of whom came from extended families, and 24 of whom came from nuclear families. The first data were collected in May 2006. The second, third and fourth set of data was obtained in May $2007,2009,2011$ when the children were in their fifth year of primary education. The TASB was applied to the 10 teachers in 2006, 18 teachers in 2007, 19 teachers in 2009 and 2011 individually in a separate room in the 12 primary schools which the children attended.

\section{RESULTS}

\section{A. Descriptive Statistics}

1) Aggression

TABLE I: DESCRIPTIVE STATISTICS OF AGGRESSION

\begin{tabular}{|c|c|c|c|c|}
\hline & Famıly Type & Mean & Std. Deviation & $N$ \\
\hline \multirow{3}{*}{6 Years } & Nuclear & 12,5417 & 5,69500 & 24 \\
\hline & Extended & 14,2174 & 6,33860 & 23 \\
\hline & Total & 13,3617 & 6,01240 & 47 \\
\hline \multirow{3}{*}{7 Years } & Nuclear & 13,0000 & 6,94700 & 24 \\
\hline & Extended & 13,6087 & 6,51390 & 23 \\
\hline & Total & 13,2979 & 6,67218 & 47 \\
\hline \multirow{3}{*}{9 Years } & Nuclear & 10,9583 & 5,30364 & 24 \\
\hline & Extended & 12,4348 & 6,11872 & 23 \\
\hline & Total & 11,6809 & 5,70319 & 47 \\
\hline \multirow{3}{*}{ 11Years } & Nuclear & 10,7500 & 5,47921 & 24 \\
\hline & Extended & 12,8261 & 6,90620 & 23 \\
\hline & Total & 11,7660 & 6,23877 & 47 \\
\hline
\end{tabular}

\section{2) Prosocial bahevior}

TABLE II: DESCRIPTIVE STATISTICS OF PROSOCIAL BEHAVIORS

\begin{tabular}{llccc}
\hline \hline & Family Type & Mean & Std. Deviation & $N$ \\
\hline \multirow{6}{*}{ 6 Years } & Nuclear & 11,4583 & 2,87386 & 24 \\
& Extended & 10,4348 & 3,31424 & 23 \\
& Total & 10,9574 & 3,10650 & 47 \\
\hline \multirow{7}{*}{7 Years } & Nuclear & 10,8333 & 3,15769 & 24 \\
& Extended & 9,3478 & 3,43258 & 23 \\
& Total & 10,1064 & 3,34426 & 47 \\
\hline \multirow{4}{*}{9 Years } & Nuclear & 11,2083 & 2,81269 & 24 \\
& Extended & 10,7391 & 3,12202 & 23 \\
& Total & 10,9787 & 2,94507 & 47 \\
\hline \multirow{7}{*}{ 11Years } & Extended & 10,0870 & 2,48474 & 23 \\
& Total & 10,6809 & 2,86741 & 47 \\
\hline \hline
\end{tabular}

3) Shyness

TABLE III: DESCRIPTIVE STATISTICS OF SHYNESS

\begin{tabular}{clccc}
\hline \hline \multirow{6}{*}{ 6 Years } & Family Type & Mean & Std. Deviation & $N$ \\
\hline \multirow{7}{*}{7 Years } & Nuclear & 6,4583 & 1,76879 & 24 \\
& Extended & 7,2174 & 2,87555 & 23 \\
& Total & 6,8298 & 2,38035 & 47 \\
\hline \multirow{7}{*}{9 Years } & Nuclear & 6,1250 & 2,59284 & 24 \\
& Extended & 7,5652 & 2,48314 & 23 \\
& Total & 6,8298 & 2,61533 & 47 \\
\hline \multirow{7}{*}{ 11Years } & Nuclear & 6,5417 & 2,24537 & 24 \\
& Total & 6,4348 & 3,21680 & 23 \\
& Nuclear & 5,4167 & 2,18526 & 24 \\
& Total & 6,4894 & 2,73363 & 47 \\
\hline \hline
\end{tabular}

\section{4) Stability of aggression in children at 6 to 11 years of} age

Predictions of changes in aggression scores from age 6 to age 11 were examined. The results indicated that aggression at age 6 was a significant predictor of aggression behavior at age $11(F=23.28, p<.001$. see Table I). Notably, there was a significant level of stability $(r=.79, p<.001)$ in aggression behavior over time.

The results of the one-way repeated measures ANOVA supported the aggression behaviors' stability. The findings showed that there were no significant differences between the scores for aggression at ages 6 to $11(F=23.28, p>.001)$. 
TABLE IV: REGRESSION EQUATIONS PREDICTING SOCIAL BEHAVIORS AT 11 YEARS FROM SOCIAL BEHAVIORS AT 6 YEARS

\begin{tabular}{lcccc}
\hline \hline & $\beta$ & $R^{2}$ & $\Delta R^{2}$ & $F$ \\
\hline $\begin{array}{l}\text { Aggression } \\
(n=47)\end{array}$ & .79 & .62 & .59 & $23.28^{* *}$ \\
$\begin{array}{l}\text { Shyness } \\
(n=47)\end{array}$ & .31 & .10 & .04 & 1.57 \\
$\begin{array}{l}\text { Prosocial beh. } \\
(n=47)\end{array}$ & .54 & .29 & .24 & $5.74^{*}$ \\
\hline \hline$p<.01, * * p<.001$ & & & & \\
\hline \hline
\end{tabular}

5) Stability of shyness in children at 6 to 11 years of age

Predictions of changes in aggression scores from age 6 to age 11 were examined. The results indicated that shyness at age 6 was not a significant predictor of shyness at age $11(F=$ $1.57, p>.05$. see Table I). Notably, there was not a significant level of stability $(r=.31, p>.05)$ in shyness over time.

On the other hand, the results of the one-way repeated measures ANOVA supported the shyness non-stability. The findings showed that there was significant differences between the scores for shyness at ages 6 to 11

6) Stability of prosocial behavior in children at 6 to 11 years of age

Predictions of changes in prosocial behaviors' scores from age 6 to age 11 were examined. The results indicated that prosocial behaviors' at age 6 was a significant predictor of prosocial behaviors at age $11(F=5.74, p<.01$. see Table I). Notably, there was a significant level of stability $(r=.54, p$ $<01)$ in aggression behavior over time.

On the other hand, the results of the one-way repeated measures ANOVA supported the aggression behaviors' stability. The findings showed that there were no significant differences between the scores for aggression at ages 6 to 11 $(F=5.74, p>.01)$.

TABLE V: STABILITY OF SOCIAL BEHAVIORS FROM 6 TO 11 YEARS

\begin{tabular}{lccccc}
\hline \hline & & $\mathrm{M}$ & $\mathrm{SD}$ & $F$ & Sig. \\
\hline Aggression & 6 years & 13.36 & 6.01 & & \\
$(n=47)$ & 7 years & 13.30 & 6.67 & $23.28^{* * *}$ & .000 \\
& 9 years & 11.68 & 5.70 & & \\
& 11 years & 11.77 & 6.24 & & \\
\hline \multirow{2}{*}{ Shyness } & 6 years & 6.83 & 2.38 & & \\
$(n=47)$ & 7 years & 6.83 & 2.62 & 1.57 & .211 \\
& 9 years & 6.49 & 2.73 & & \\
& 11 years & 5.72 & 2.4 & & \\
\hline \multirow{2}{*}{ Prosocial } & 6 years & 10.95 & 3.11 & & .002 \\
Behaviors & 7 years & 10.11 & 3.34 & $5.74^{*}$ & \\
$(n=47)$ & 9 years & 10.68 & 2.87 & & \\
& 11 years & 10.98 & 2.95 & & \\
\hline \hline
\end{tabular}

\section{7) Family types and aggression}

Repeated measures ANOVA with a Greenhouse-Geisser correction determined that mean not differed statistically significantly between aggression's $(F(2.19,98.56)=$ $235, P>0.05)$ time points and family types.

\section{8) Family types and shyness}

Repeated measures ANOVA with a Greenhouse-Geisser correction determined that mean not differed statistically significantly between shyness' $(F(2.92,131.58)=.982, P>$ $0.05)$ time points and family types.

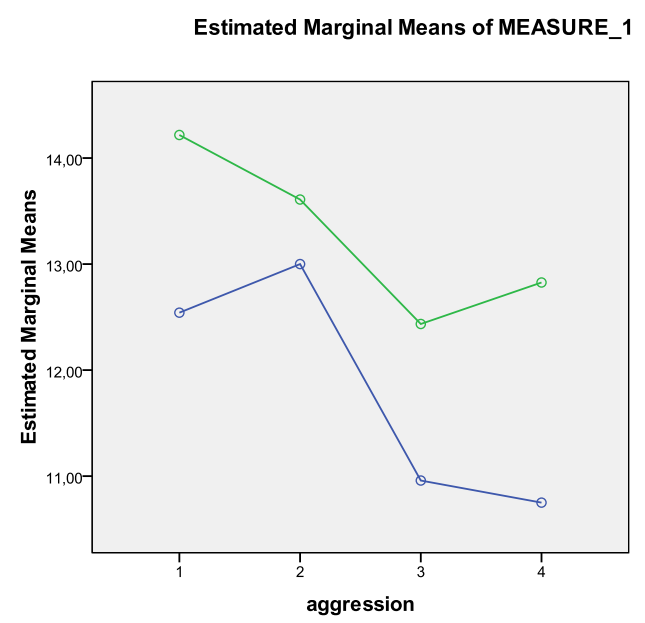

FAMILYTYPE — NUCLEAR

Fig. 1. Time points and family types for aggression.

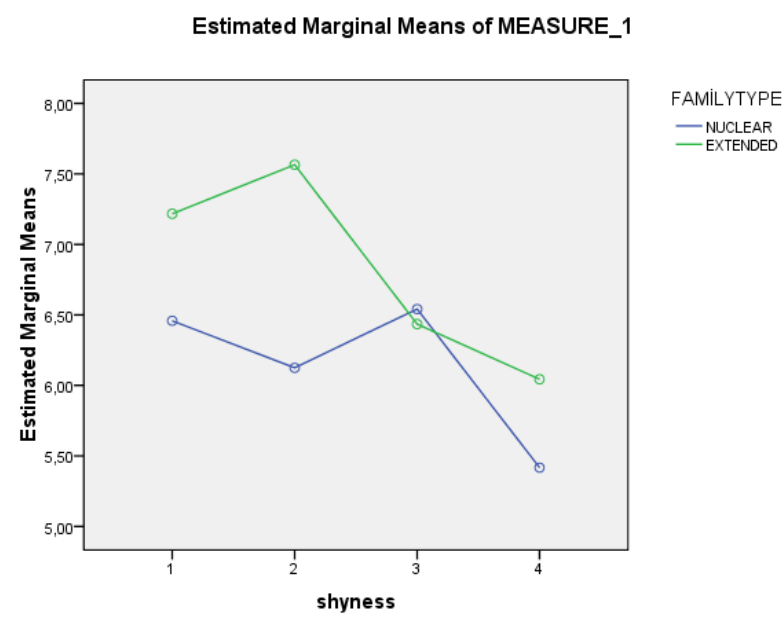

Fig. 2. Time points and family types for shyness.

\section{9) Family types and prosocial behavior}

Repeated measures ANOVA with a Greenhouse-Geisser correction determined that mean not differed statistically significantly between prosocial behaviours' $(F(2.63,118.67)$ $=.383, P>0.05)$ time points and family types.

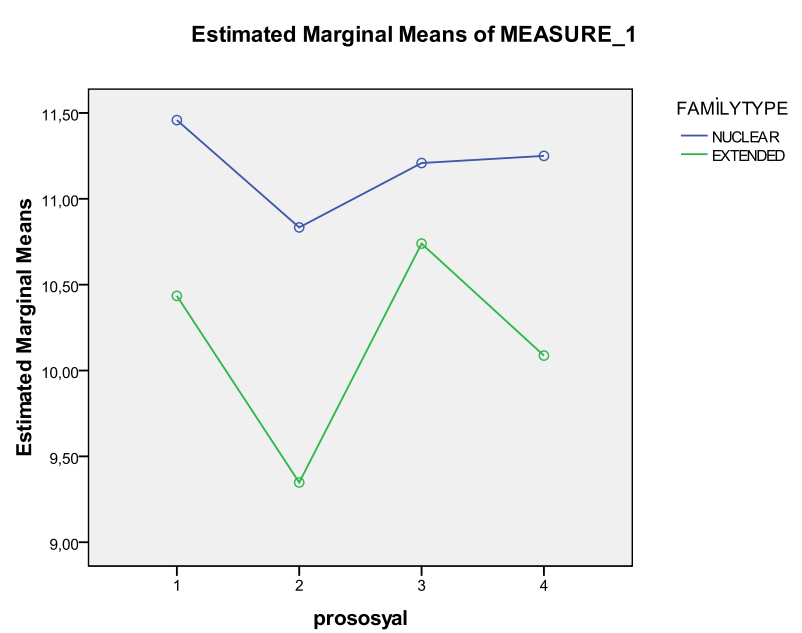

Fig. 3. Time points and family types for prosocial behaviours. 


\section{DiscUSSION}

This study examined the stability of children's aggression, shyness and prosocial behaviors a five-year period, from age 6 to age 11. The results of the present study show a significant degree of stability of aggression and prosocial behaviors from age 6 to age 11 . Whereas, There was no a significant degree of stability was found for shyness. In conclusion, social behavior was found to be stable for $55 \%$ prosocial behaviors, 31\% Shyness behavior and $79 \%$ for aggressive behavior as results of regression analysis. These findings support the argument that aggression [23], [29], [2], [30] and prosocial behaviors [31]. Follows a stable course from age 6-11 age onwards and shyness Asendorpf [4], Degnan et. al. [26], Prior et al [27] and Roberts and del Vecchio [28] follows low stability.

Repeated measures ANOVA with a Greenhouse-Geisser correction determined that mean not differed statistically significantly between aggression's $(F(2.19,98.56)=$ $235, P>0.05)$, shyness' $(F(2.92,131.58)=982, P>0.05)$ and prosocial behaviours' $(F(2.63,118.67)=383, P>0.05)$ time points and family types.

This research has some limitations. The research tools were limited to the TASB scale. Different social behaviors scales should be used and adapted into Turkish in future studies. In this study, social behaviors were determined in line with the opinions of children. However, different and numerous techniques such as observation and peer opinions may be used in future studies. In this study, social behaviors were analysed in terms of stability.

Some proposals have been developed in light of the present study's results. In this respect, first, it is proposed that new scales that measure social behaviors such as aggression, shyness and prosocial behaviors from early childhood to adolescence should be developed in order to conduct studies using different age groups. The results of the present study demonstrate that aggression and prosocial behavior have stability tendency from 6 to 11 . Therefore, studies should be carried out on family subjects such as child education, mother-child interaction and childcare. In line with the studies indicating that social behaviours may change depending on culture, studies should be conducted in order to investigate the forms and continuity of social behaviors in the Turkish culture and other cultures.

\section{ACKNOWLEDGMENT}

I would like to acknowledge the help of Jude Cassidy. I would also like to thank all of the participating children and their parents.

\section{REFERENCES}

[1] G. Parker and S. R. Asher, "Peer relations and later personal adjustment: are low-accepted children at risk?" Psycological Bulletin, vol. 102, no. 3, pp. 357-389, 1987.

[2] R. Loeber and D. Hay, "Key issues in the development of aggression and violence from childhood to early adulthood," Annual Review of Psychology, vol. 48, pp. 371-410, 1997.

[3] M. W. Kempes, H. M. Vries, and H. V. Engeland, "Reactive and proactive aggression in children," A Reviw of Theory, Findins and Relevance for Child and Adolescent Psychiatry, European Child \& Adolescence Psychiatry, vol. 14, pp. 11-19, 2005.
[4] M. A. Bruch, J. M. Gorsky, T. M. Collins, and P. A. Berger, "Shyness and sociability reexamined: a multicomponent analysis," Journal of Personality and Social Psychology, vol. 57, pp. 904-915, 1989.

[5] D. C. Beidel, S. M. Turner, and T. L. Morris, "Psychopathology of childhood social phobia," Journal of the American Academy of Child and Adolescent Psychiatry, vol. 38, pp. 643-650, 1999.

[6] R. J. Coplan and M. Armer, "A 'multitude' of solitude: A closer lookat social withdrawal and nonsocial play in early childhood," Child Development Perspectives, vol. 1, no. 1, pp. 26-32, 2007.

[7] A. Sanson, R. Pedlow, W. Cann, M. Prior, and F. Oberklaid, "Shyness ratings: Stability and correlates in early childhood," International Journal of Behavioral Development, vol. 19, pp. 705-724, 1996.

[8] R. J. Coplan, K. Prakash, K. O’Neil, and M. Armer, "Do you "want" to play? Distinguishing between conflicted shyness and social disinterest in early childhood," Developmental Psychology, vol. 40, pp. 244-258, 2004.

[9] N. Eisenberg, S. Shepard, R. A. Fabes, B. Murphy, and I. Guthrie, "Shyness and children's emotinality, regulation, and coping: Contemporaenous, longitudinal, and across- context relations," Child Development, vol. 68, pp. 767-790, 1998.

[10] E. Fehr and U. Fischbacher, "The nature of human altruism," Nature, vol. 425, pp. 785-791, 2003.

[11] N. Eisenberg and R. A. Fabes, "Prosocial development," in Handbook of Child Psychology: Social, Emotional, and Personality Development, W. Damon and N. Eisenberg ed., New York: Wiley, 1998, vol. 3, pp. 701-778.

[12] E. Staub, Positive Social Behavior and Morality: Socialization and Development, New York: Academic Press, vol. 2, 1979.

[13] K. E. Clark and G. W. Ladd, "Connectedness and autonomy support in parent- child relationships: links to children's socioemotional orientation and peer relationships," Developmental Psychology, vol. 36, pp. 485-498, 2000

[14] R. A. Fabes, J. Fultz, N. Eisenberg, and T. M. Plumlee, "Effects of rewards on children's prosocial motivation: A socialization study," Developmental Psychology, vol. 25, pp. 509-515, 1989.

[15] J. E. Grusec, J. J. Goodnow, and L. Cohen, "Household work and the development of concern for others," Developmental Psychology, vol. 32, pp. 999-1007, 1996.

[16] B. Karsl1, "The effects of the reality shows and women programs in the media on Turkish family structure the Erzurum model," Erzurum, Turkey: Unpublished master's thesis, Ataturk University, 2006.

[17] M. D. Topses, "The connection between modern family structure=functions and altruistic behavior of individuals," Ankara, Turkey: Unpublished doctoral dissertation, Hacettepe University, 2008.

[18] S. Yavuz, "Changing household and family compositions in Turkey: a demographic evaluation for 1968-1998 period," Hacettepe University E-Journal of Sociological Research, vol. 2, pp. 1-34, 2004.

[19] N. Adak, "Foundation stone of society: Family," in A Sociological Overview of Institutions, S. Güçlü ed., Istanbul, Turkey: Birey, 2005, pp. $150-170$.

[20] S. Budak, Dictionary of Psychology, Ankara, Turkey: Science and Art Publications, 2000.

[21] R. S. Marvin and R. B. Stewart, "A family systems framework for the study of attachment," in Attachment in the Preschool Years: Theory, Research, and Intervention, M. T. Greenberg, D. Cicchetti, and E. M Cummings ed., Chicago, IL: Chicago University Press, 1990, pp. 3-49.

[22] F. Merter, Changes Observed in a Village Family between 1950-1988, Ankara, Turkey: The Presidency of Family Research Association Publications, 1990.

[23] R. Adams, W. Bukowski, and C. Bagwell, "Stability of aggression during early adolescence as moderated by reciprocated friendship status and friend's aggression," International Journal of Behavioral Development, vol. 29, no. 2, pp. 139-145, 2005.

[24] M. Armer, "Running head: Stability and outcomes of shyness," Unpublished master thesis, Canada: Carleton University, Ottowa, 2003.

[25] J. B. Asendorpf, "Long-term development of shyness: Looking forward and looking backward," in the Development of Shyness and Social Withdrawal, K. H. Rubin and R. J. Coplan ed., New York: Guilford, pp.157-175.

[26] K. A. Degnan, H. A. Henderson, N. A. Fox, K. H. Rubin, and K. Nichols, "Predicting social wariness in middle childhood: the moderating roles of childcare history, maternal personality and maternal behavior," Social Development, vol. 17, pp. 471-487, 2008.

[27] M. Prior, D. Smart, A. Sanson, and F. Oberklaid, "Does shy-inhibited temperament in childhood lead to anxiety problems in adolescence?" 
Journal of the Academy of Child and Adolescent Psychiatry, vol. 39, pp 461-468, 2000

[28] B. W. Roberts and W. F. Delvecchio, "The rank-order consistency of personality traits from childhood to old age: a quantitative review of longitudinal studies," Psychological Bulletin, vol. 126, no. 1, pp. 3-25, 2000.

[29] R. Loeber, "The stability of antisocial and delinquent child behavior: a review," Child Development, vol. 53, pp. 1431-1446, 1982.

[30] D. Olweus, "Stability of aggressive reaction patterns in males: a review," Psychological Bulletin, vol. 86, pp. 852-875, 1979.

[31] A. Knafo and R. Plomin, "Prosocial behavior from early to middle childhood: genetic and environmental influences on stability and change," Developmental Psychology, vol. 42, no. 5, pp. 771-786, 2006.

[32] S. Seven, "Adaptation of teacher assessment of social behavior scale to Turkish culture," Selçuk University the Journal of Institute of Social Science, vol. 23, pp. 193-200, 2010.

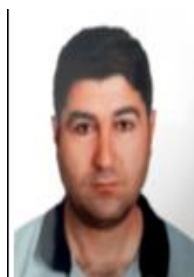

Serdal Seven was born in Muş Turkey in 1977. He received the B.A. degree in social science education, Celal Bayar University, Manisa, Turkey, 1999, M.A. degree in social science education, Celal Bayar University, Manisa, Turkey, 2001, and Ph.D. degree in child development and education, Gazi University, Ankara, Turkey, 2006.

$\mathrm{He}$ worked as a teacher in Manisa and Muş,
2000-2007, he was an associater professor in Muş Alparslan University, Muş, Turkey, 2007-2011, associater professor in Kent State University, Ohio, USA, 2011, associater professor in Muş Alparslan University, Muş, Turkey, 2012-2013, and associater professor in Muş Alparslan University, Muş, Turkey, 2013.

Mr. Seven has three awards from the scientific and technological research council of Turkey.

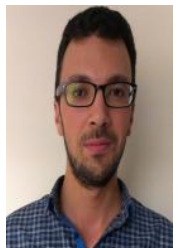

Mehmet Akif İnci was born in Van Turkey in 1986. He received the B.A. degree in early childhood education, Yüzüncü Yıl University, Van, Turkey, 2010 and M.A degree in early childhood education, Gazi University, Ankara, Turkey, 2014

He works as a research assistant in Mus Alparslan University, Muş, Turkey, 2010. 